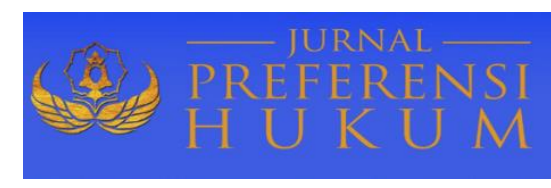

Jurnal Preferensi Hukum | ISSN: 2746-5039

Vol. 2, No. 1 - Februari 2021, Hal. 109-113| Available online at https://www.ejournal.warmadewa.ac.id/index.php/juprehum

DOI: https://doi.org/10.22225/jph.2.1.3055.109-113

\title{
PELAKSANAAN DISIPLIN APARATUR SIPIL NEGARA DI LINGKUNGAN PEMERINTAH KABUPATEN KLUNGKUNG
}

\author{
Ni Putu Ayu Sutarini Dewi, I Gst Bgs Suryawan, Luh Putu Suryani \\ Fakultas Hukum Universitas Warmadewa, Denpasar-Bali, Indonesia
}

\begin{abstract}
Abstrak
Demi terwujudnya tujuan nasional, Aparatur Sipil Negera (ASN) bertugas memberikan pelayanan publik. Dalam melayani masyarakat, masih banyak ASN yang kinerjanya kurang memuaskan dalam melayani masyarakat serta banyak ASN yang melanggar peraturan disiplin. Pelanggaran disiplin Aparatur Sipil Negara diantaranya adalah tidak mentaati kewajiban dan atau melanggar larangan ketentuan disiplin ASN, baik yang dilakukan di dalam maupun di luar jam kerja. Penelitian ini bertujuan untuk penerapan hukuman terhadap Aparatur Sipil Negara yang melakukan pelanggaran disiplin dan faktor penghambat dalam penjatuhan sanksi. Metode yang digunakan dalam penelitian ini adalah dengan penelitian Empiris dengan bahan hukum primer dan sekunder serta teknik pengumpulan bahan hukum dengan turun langsung kelapangan, wawancara dan studi kepustakaan. Hasil dari penelitian adalah penerapan hukuman terhadap ASN yang melanggar aturan disesuaikan dengan tingkat pelanggaran yang dilakukan dan penerapannya sesuai dengan Undang-Undang No. 53 tahun 2010. Faktor-faktor yang menjadi penghalang didalam pelaksanaan penjatuhan sanksi di Lingkungan Pemerintah Kabupaten Klungkung yaitu disebabkan karena kurang tegasnya sikap atasan dan masih tingginya tingkat nepotisme atau sistem kekeluargaan juga kondisi politik dilingkungan pemerintah Kabupaten Klungkung pada umumya dan kantor Sekda bagian Humas pada khususnya. Berdasarkan hasil penelitian diatas, peneliti menyarankan perlunya peningkatan pengawasan secara langsung dari atasan maupun pihak-pihak terkait.
\end{abstract}

Kata Kunci: ASN, Penerapan Sanksi; Penghambat Sanksi

\begin{abstract}
In order to realize national goals, Aparatur Sipil Negara ASN is in charge of providing public services. In serving the community, there are still many ASNs whose performance is not satisfactory in serving the community and many ASNs that violate disciplinary regulations. Discipline violations of the State Civil Apparatus include disobeying obligations and or violating the prohibition of the provisions of the ASN discipline, both those carried out inside and outside working hours. The problem of this research is about the application of penalties to the State Civil Apparatus who violate discipline and inhibiting factors in imposing sanctions. The method used in this study is empirical research with primary and secondary legal materials and legal material collection techniques by directly dropping space, interviews and literature studies. The results of the study were the application of penalties against ASN that violated the rules according to the level of violations committed and applied in accordance with Law No. 53 of 2010. The factors that become a barrier in the implementation of sanctions in the Klungkung Regency Government Environment are caused by the lack of strict attitude of the superiors and the high level of nepotism or kinship system as well as the political conditions in the Klungkung Regency government in general and the Secretariat in particular .
\end{abstract}

Keywords: ASN, Application of Sanctions, Sanctions Barriers

\section{PENDAHULUAN}

Pembinaan harus dilakukan demi terwujudnya ASN yang professional dan bertanggung jawab, hal ini dilakukan atas dasar sistem karier serta sistem prestasi kerja. Sebuah sistem karier di sini dapat dikatakan bahwa suatu proses pengangkatan terhadap seorang pegawai berdasarkan atas prestasi, ketrampilan dan kepandaian juga kedisiplinan dan menjadi pertimbangan adalah masa kerja, pengabdian dan lain sebagainya (Dhahri, Kasmawati, \& Bakhtiar, 2017). Sedangkan yang dimaksud dengan Sistem prestasi kerja yang diterapkan ialah tahapan dimana seorang pegawai akan diangkat untuk menduduki jabatan tertentu atau naik pangkat berdasarkan dari prestasi kerjanya (Putra \& Sudiarta, 2019).

Masih banyaknya ASN yang kinerjanya kurang memuaskan dalam melayani masyarakat serta banyak ASN yang melanggar peraturan disiplin menjadi permasalahan pada masa sekarang ini. Permasalahan yang paling sering terjadi adalah mengenai disiplin waktu. Contohnya banyak ASN 
mangkir dan bolos dari kerja dengan alasan yang tidak jelas, serta ada ASN yang perbuatannya telah melawan hukum dan dapatdijatuhi hukuman (Pio, 2018). Pengalokasian dana yang cukup besar dari pemerintah dan pelaksanaan kegiatan pelatihan bagi Aparatur Sipil Negara agar kinerjanya bisa sesuai yang diharapkan ternyata belum mampu membuat ASN berubah menjadi disiplin, Sertaupaya pemberian motivasi dengan pemberian kesejahteraan yaitu dengan pemberian tunjangan-tunjangan dan kenaikan gaji dan upaya penegakan disiplin Aparatur Sipil Negara yang selalu dilakukan (Sukmajadi, 2019). Pelanggaran Disiplin yang terjadi di Kantor Bagian Humas Pemerintah Kabupaten Klungkung dikarenakan banyaknya hal sehingga menyebabkan terjadi banyak pelanggaran. Pelanggaran tersebut terus saja berulang-ulang karena tidak adanya penyesalan bagi ASN yang melakukan pelanggaran dan hukuman disiplin kurang memberikan efek jera pada ASNyang terkait, yaitu pelanggaran terkait dengan disiplin waktu kerja maupun hal-hal lain yang terkait dengan disiplin Aparatur Sipil Negara.

Berdsarkan uraian di atas, maka penelitian ini bertujuan untuk mengetahui pelaksanaan atau penerapan Undang-Undang No. 53 Tahun 2010 tentang Disiplin ASN apakah telah efektif dan Efisien dan mengetahui cara dan Hambatan Pelaksanaan Penjatuhan Sanksi Terhadap Aparatur Sipil Negara di lingkungan Pemerintah Kabupaten Klungkung berdasarkan Undang-Undang No. 53 Tahun 2010.

\section{METODE PENELITIAN}

Penelitian ini dilakukan secara Empiris dengan pendekatan secara kualitatif di Kantor Bagian Humas Pemerintah Kabupaten Klungkung, selain itu juga melalui studi kepustakaan dengan membaca, mengkaji, serta menelaan buku-buku, peraturan perundang-undangan, dan media internet (Soekanto \& Mamudji, 2003). Sumber data menggunakan sumber primer dan sekunder, sumber data primer diperoleh dari hasil penelitian di lapangan yakni di lingkungan Kantor Bagian Humas Pemerintah Kabupaten Klungkung, dengan mengadakan wawancara terhadap pihak-pihak yang terkait. Sedangkan data sekunder diperoleh dari melaah buku, Peraturan Perundang-undangan, literatur, jurnal atau artikel juga internet. Alat penumpulan data yang digunakan dalam penetian ini yaitu: a. Observasi yaitu dengan terjun langsung ke lokasi penelitian. b. Wawancara (interview), yaitu dengan melakukan tanyajawab dengan Kepala Sub.Bagian, dan para pegawai di Kantor Bagian Humas Pemerintah Kabupaten Klungkung. c. Studi kepustakaan, yaitu mengkaji dan menelaah dokumen hasil penelitian, Buku, Undang-Undang dan Internet. Analisis data dilakukan secara deskriptif kualitatif yaitu dengan mengelompokkan data yang diperoleh dari lapangan kemudian dibahas dan di uji kebenarannya (Soekanto \& Memudji, 2003).

\section{HASIL DAN PEMBAHASAN}

\section{Penerapan Hukuman terhadap Aparatur Sipil Negara yang Melakukan Pelanggaran Disiplin di Lingkungan Pemerintah Kabupaten Klungkung}

1) Penegakan Aturan Disiplin Aparatur Sipil Negara

Cermin disiplin yang baik dapat dilihat dari tingkat ketaatan atau kepatuhan seorang pegawai dalam mentaati aturan dan menjalankan tugas yang diberikan atasan serta selalu menjaga ketertiban dalam bekerja. Aturan Penegakan disiplin Aparatur Sipil Negara mempunyai tolak ukur tersendiri diantaranya mentaati kewajiban dan menjauhi larangan sesuai dengan Peraturan PerundangUndangan tentang Disiplin ASN.

Terdapat 17 butir kewajiban dan 15 butir larangan yang harus di patuhi oleh seluruh ASN, hal ini senada Undang-Undang No. 53 Tahun 2010 tentang Disiplin ASN. Penulis dalam hal ini hanya fokus mengulas mengenai beberapa butir kewajiban dan larangan saja, diantaranya adalah sebagai berikut:

a. Kewajiban

1. Selalu taat terhadap ketentuan jam kerja. Pengamatan dilapangandidapat hasil bahwa cukup banyak pegawai dilingkungan Kantor Bagian Humas Pemerintah Kabupaten Klungkungyang datang terlambat. Aturan jam kerja ditetapkan pukul 07.30 wita namun masih cukup banyak pegawai yang datang diatas jam yang sudah ditentukan. Aturan jam pulang pukul 15.30 wita, tetapi banyak juga pegawai yang pulang sebelum jam tanpa alasan yang jelas. Hal ini menunjukkan beberapa pegawai di Kantor Bagian Humas Pemerintah Kabupaten Klungkung kurang mentaati peraturan jam kerja dan dikatakan kalau tingkat kedisiplinan terhadap jam kerja masih rendah.

2. Memenuhi sasaran kerja pegawai yang ditetapkan. Secara umum penetapan rencana kerja di 
Kantor Bagian Humas Pemerintah Kabupaten Klungkung telah terstruktur dengan baik, dari hasil pengamatan meskipun masih terdapat banyak pegawai yang kurang disiplin waktu tetapi dalam pencapaian sasaran kerja telah mencapai sasaran yang ditetapkan serta menunjukkan kinerja yang cukup memuaskan.

3. Menciptakan pelayanan yang cukup baikbagi masyarakat. Keluhan dari masyarakat dalam hal ini masih tinggi, masyarakat merasa pelayanan ASN masih kurang terhadap masyarakat. Karena itulah pemerintah Kabupaten Klungkung mencoba membangun kembali tingkat kepercayaan publik terhadap kinerja pemerintah daerah.

b. Larangan

1. Tidak diperbolehkannya menerima suatu pemberian dalam bentuk apapun yang berhubungan dengan jabatan maupun pekerjaan. Setiap ASN dilingkungan Pemerintah Kabupaten klungkung, Khususnya kantor Bagian Humas sangat dilarang untuk menerima hadiah karena merupakan suatu gratifikasi. Hal ini lakukan demi mewujudkan suatu pemerintahan yang bersih dan bebas dari Korupsi, Kolusi dan Nepotisme.

2. Mengahalangi atau mempersulit masyarakatyang berakibat merugikan masyarakat yang dilayani. Fungsi dari sebuah pemerintahan adalah memberikan pelayanan terhadap masyarakat, seluruh ASN wajib melayani masyarakat tanpa harus membedakan suku, agama dan ras, di lingkungan pemerintah Kabupaten Klungkung hal tersebut tidak terjadi karena seluruh ASN telah bekerja sesuai prosedur.

3. Melakukan sesuatu dengan menjanjikan atau memberikan kepada siapapun serta dengan alasan apapun untuk diangkat dalam jabatan. Pegawai di Kantor Bagian Humas Pemerintah Kabupaten Klungkungdalam pengangkatan jabatan sudah sesuai dengan aturan yang berlaku. Prosedur pengangkatan atau kenaikan jabatan dilaksanakan berdasarkan aturan Perundangundangan yang berlaku.

2) Penerapan Hukuman Disiplin Aparatur Sipil Negara Di Kantor Bagian Humas Pemerintah Kabupaten Klungkung

Pemberian Hukuman disiplin Di Kantor Bagian Humas Pemerintah Kabupaten Klungkungdijatuhkan kepada Aparatur Sipil Negara berdasarkan atas pelanggaran yang dilakukan karena melanggar peraturan disiplin ASN. Tinggi atau rendahnya kualitas disiplin ASN ditentukan oleh ASN itu sendiri. Sebab itulah sanksi disiplin perlu diberikan kepada ASN yang melanggar aturan dengan tujuan supaya ASN yang tersebut bisa menjadi seorang Aparat Negara yang patuh terhadap aturan. Adapun data ASN yang dijatuhi sanksi atau hukuman disiplin di Kantor Bagian Humas Pemerintah Kabupaten Klungkungdapat dilihat pada Tabel 1.

Tabel 1.

Data Pegawai Kantor Bagian Humas Pemerintah Kabupaten Klungkung yang dijatuhi hukuman disiplin tahun 2014-2018

\begin{tabular}{|c|c|c|c|c|c|c|c|}
\hline No & $\begin{array}{c}\text { Tingkat Hukuman } \\
\text { Disiplin }\end{array}$ & $\begin{array}{c}\text { Tahun } \\
\mathbf{2 0 1 4}\end{array}$ & $\begin{array}{c}\text { Tahun } \\
\mathbf{2 0 1 5}\end{array}$ & $\begin{array}{c}\text { Tahun } \\
\mathbf{2 0 1 6}\end{array}$ & $\begin{array}{c}\text { Tahun } \\
\mathbf{2 0 1 7}\end{array}$ & $\begin{array}{c}\text { Tahun } \\
\mathbf{2 0 1 8}\end{array}$ & Jumlah \\
\hline 1 & Ringan & 7 & 8 & 5 & 3 & 2 & 25 \\
\hline 2 & Sedang & - & - & - & - & - & - \\
\hline 3 & Berat & 1 & 1 & - & - & - & 2 \\
\hline & Jumlah & 8 & 9 & 5 & 3 & 2 & 27 \\
\hline
\end{tabular}

Sumber: Kantor Sekretariat Daerah dan Kantor Bagian Humas PemerintahKabupaten Klungkung.

Berdasarkan hal tersebut dapat disimpulkan bahwa penerapan sanksi di Kantor Bagian Humas Pemerintah Kabupaten Klungkung telah sesuai dengan Undang-Undang dan aturan disiplin ASN, hukuman diberikan berdasarkan dari tingkat pelanggaran yang dilakukan.

2. Faktor-Faktor yang Menjadi Penghambat Pelaksanaan Penjatuhan Sanksi Pelanggaran Disiplin Terhadap Aparatur Sipil Negara di Kantor Bagian Humas Pemerintah Kabupaten Klungkung

1. Faktor Yuridis 
Menurut, Soekanto (2004), terkait faktor-faktor yuridis pelaksanaan disiplin ASN adalah:

a) Faktor hukumnya sendiri.

b) Faktor penegak hukum.

c) Faktor sarana / fasilitas yang mendukung penegakan hukum.

d) Faktor masyarakat.

2. Faktor Non Yuridis

Beberapa faktor-faktor non yuridis yang mempengaruhi penegakan disiplin ASN antara lain:

a. Faktor Sarana dan Prasarana

Faktor sarana dan prasarana sangat berpengaruh terhadap tingkat kedisiplinan Aparatur Sipil Negara, karena itulahdi lingkungan Kantor Bagian Humas menerapkan penggunaan mesin absensi retina mata atau Scan wajah.

b. Apresiasi atau Penghargaan untuk Aparatur Sipil Negara (Sastrohadiwiryo, 2010).

Penghargaan Satya Lencana selalu di berikan oleh Pemerintah Kabupaten Klungkung kepada ASN yang melaksanakan tugasnya secara terus menerus sekurang-kurangnya telah bertugas selama 10 tahun sampai 30 tahun.

3. Faktor yang menjadi penghambat

Dalam pelaksanaan penjatuhan sanksi administrasi di Kantor Bagian Humas Pemerintah Kabupaten Klungkung, ada beberapa kendala dan hambatan. Faktor-faktor itu antara lain:

a. Selalu diberikannya toleransi yang dilakukan oleh atasan, artinya setiap pelanggaran yang dilakukan terkadang kurang diberikan teguran atau sanksi yang tegas dari atasan.

b. Didalam melaksanakan kewajiban dan berkomitmen untuk tidak melakukan pelanggaran disiplin tingkat kesadaran ASN sangat kurang.

c. Politik, dalam penjatuhan sanksi situasi politik sering menjadi penghambat di lingkungan pemerintah Kabupaten Klungkungkarena masih kental dengan Nepotisme.

\section{SIMPULAN DAN SARAN}

\section{Simpulan}

Penerapan sanksi disiplin di lingkungan Pemerintah Kabupaten Klungkung khususnya di Kantor Setda Bagian Humas sudah sesuai dengan aturan disiplin ASN, sanksi diberikan kepada pegawai yang melakukan pelanggaran dan tingkat hukuman berdasarkan dari pelanggaran yang dilakukan. Kemudian, penghambat penjatuhan sanksidi lingkungan Pemerintah Kabupaten Klungkung khususnya di Kantor Setda Bagian Humas, karena masih adanya toleransiyang diberikan pimpinan atau atasan, kurang taatnya ASN terhadap peraturan dan disiplin, serta situasi politik yang menyebabkan masih kentalnya budaya nepotisme.

\section{Saran}

Perlunya peningkatan pengawasan secara langsung dari atasan maupun pihak-pihak terkait. Menjatuhkan sanksi kepada seluruh ASN yang melanggaran aturan tanpa melihat asal-usul dan keluarga maupun koneksi seseorang dalam pemerintahan. Kepala Badan Kepegawaian Daerah Kabupaten Klungkung Perlu perlu melkukan sosialisasi terhadap peraturan kepada seluruh ASN Pemerintah Kabupaten Klungkung, supaya seluruh pegawai dapat memahami dan patuh.

\section{DAFTAR PUSTAKA}

Dhahri, I., Kasmawati, A., \& Bakhtiar. (2017). Pemahaman Nilai-Nilai dasar Profesi Universitas Negeri Makassar. Jurnal Supremasi, 12(2), 90-104.

Pio, E. R. C. (2018). Tanggung Jawab Administrasi Aparatur Sipil Negara terhadap Perbuatan Melawan Hukum dalam Menjalankan Kewenangannya. Lex Administratum, VI(4), 111-121.

Putra, F. B. M. L., \& Sudiarta, I. K. (2019). Pelaksanaan Sistem Kenaikan Pangkat dalam Jabatan Struktural di Lingkungan Pemerintahan Provinsi Bali. Kertha Negara, 7(9), 1-15.

Sastrohadiwiryo, B. S. (2010). Manajemen Tenaga Kerja Indonesia. Jakarta: Bumi Aksara.

Soekanto, S. (2004). Faktor-Faktor Yang Mempengaruhi Penegakan Hukum (Cetakan Ke). Jakarta: Raja Grafindo Persada.

Soekanto, S., \& Mamudji, S. (2003). Penelitian Hukum Normatif: Suatu Tinjauan Singkat. Jakarta: Rajawali Press.

Soekanto, S., \& Memudji, S. (2003). Penelitian Hukum Empiris. Jakarta: UI Press. 
Sukmajadi, B. (2019). Peran Diklat Revolusi Mental terhadap Peningkatan Profesionalisme ASN dalam Pelayanan Publik di Lingkungan Pemerintah Provinsi DKI Jakarta. Monas: Jurnal Inovasi Aparatur, 1(1), 30-38.

Undang-Undang Nomor 5 Tahun 2014 tentang Aparatur Sipil Negara, (Lembaran Negara Republik Indonesia Tahun 2014 Nomor 6, Tambahan Lembaran Negara Republik Indonesia Nomor 5494).

Peraturan Pemerintah Nomor 30 Tahun 1980 tentang Peraturan Disiplin Pegawai Negeri Sipil.

Peraturan Pemerintah Nomor 53 Tahun 2010 tentang disiplin Pegawai Negeri Sipil.

Peraturan Pemerintah Nomor 53 Tahun 2010 tentang Disiplin Pegawai Negeri Sipil, (Lembaran Negara Republik Indonesia Tahun 2010 Nomor 74, Tambahan Lembaran Negara Republik Indonesia Nomor 5135). 